\title{
MODELOS DIDÁTICOS E MAPAS CONCEITUAIS: BIOLOGIA CELULAR E AS INTERFACES COM A INFORMÁTICA EM CURSOS TÉCNICOS DO IFMS
}

\author{
A. J. VINHOLI JÚNIOR ${ }^{1}$ e G. C. PRINCIVAL ${ }^{2}$ \\ Instituto Federal de Educação, Ciência e Tecnologia de Mato Grosso do Sul \\ vinholi22@yahoo.com.br ${ }^{1}$; guilherme.princival@ifms.edu.br ${ }^{2}$
}

Artigo submetido em fevereiro/2014 e aceito em março/2014

\section{RESUMO}

Considerando as dificuldades inerentes ao conteúdo de Biologia celular, foi proposta a confecção e uso de modelos didáticos como meio potencialmente significativo para efetivar a aprendizagem de conceitos sobre célula em estudantes do IFMS/Ponta Porã. Procurou-se, com o uso de Mapas Conceituais, favorecer uma organização dos conhecimentos sobre essa temática, de modo a promover uma visão mais integradora do conteúdo. $O$ estudo fundamentou-se na Teoria da Aprendizagem Significativa de David Ausubel.
Com base nos conhecimentos prévios, foi preparada a sequencia didática, que se subordinou também aos princípios da diferenciação progressiva e reconciliação integrativa, utilizando Mapas Conceituais. Tais dados, após serem descritos e analisados, permitiram inferir a ocorrência da evolução conceitual e Aprendizagem Significativa. 0 trabalho demonstra união de conhecimento de área básica e técnica para contribuir com o ensino e aprendizagem em cursos de educação profissional e tecnológica do IFMS.

PALAVRAS-CHAVE: Biologia celular, Modelos didáticos, Mapas Conceituais.

\section{EDUCATIONAL MODELS AND CONCEPT MAPS: CELL BIOLOGY AND INTERFACES WITH THE COMPUTER IN TECHNICAL COURSES OF IFMS}

\begin{abstract}
Considering the difficulties concerning to cell biology content, the making and use of didactic models were proposed as a potentially significant means on the learning of cell concepts with students of IFMS / Ponta Porã. We tried, through the use of concept maps, to promote the knowledge on this topic, in order to further a more inclusive view of the content. The study was based on the Theory of Meaningful Learning David Ausubel. Based on prior knowledge, we prepared a didactic
\end{abstract}

sequence, which is also subordinated to the principles of progressive differentiation and integrative reconciliation, using concept maps. These data, after being described and analyzed, allowed us to infer the occurrence of conceptual evolution and Meaningful Learning. The work shows the association between basic and technical knowledge areas contribute to the teaching and learning in technical and professional education of IFMS.

KEYWORDS: cell biology, teaching models, concept maps. 


\section{INTRODUÇÃO}

No contexto da história da educação no Brasil, a prática docente em ciências biológicas sempre esteve voltada para a racionalidade técnica. Segundo Carvalho (2002), a atividade do profissional guiada pela racionalidade técnica tem como principal objetivo a solução de problemas mediante a aplicação rigorosa de teorias e técnicas científicas. Ou seja, a atividade docente consiste na priorização da mera transmissão de conteúdos em detrimento dos métodos que valorizem a participação e reflexão, tanto por parte dos professores quanto por parte dos estudantes (SETÚVAL e BEJARANO, 2009).

O modelo de ensino baseado nesse tipo de racionalidade, também considerado como modelo tradicional de ensino, não propicia interação entre professores e estudantes, e nem entre os próprios estudantes, dificultando que promovam a construção de conhecimentos.

Diversos estudos têm apontado a forma como o processo de modelagem pode contribuir na construção do conhecimento e preconizam que o envolvimento de estudantes em atividades com modelos didáticos ajuda a promover uma apropriação que sobrepuja a memorização e favorece o desenvolvimento de habilidades e um conhecimento crítico, aplicável em diversas situações e problemas (CLEMENT, 2000).

Em pesquisas no campo do Ensino de Ciências, a terminologia modelos tem freqüente ocorrência, no entanto, apresenta vários significados. Assim, percebe-se forte aproximação entre as metodologias empregadas para sua utilização e os tópicos a serem trabalhados, bem como a sincronia entre experimento e empiria, onde imagens e proposições estão associadas. Nestas articulações, os modelos podem ser compreendidos como um processo de representações que envolvem o uso de imagens, de forma esquematizada e concreta, para que estudantes, docentes e/ou pesquisadores possam idealizar determinado assunto científico que pode, muitas vezes, ser de difícil compreensão.

Gilbert e Boulter (1998, p. 55), propõem então que modelos sejam definidos como "a representação de uma ideia, um objeto, um evento ou um sistema" e distinguem vários modelos:

o modelo mental (uma representação pessoal, privada de um alvo), o modelo expresso (aquela versão de um modelo mental que é expressa por um indivíduo através da ação, fala ou escrita), o modelo consensual (um modelo expresso que foi submetido a teste por um grupo social, por exemplo a comunidade científica, e que é visto, pelo menos por alguns, como tendo mérito), e o modelo pedagógico (um modelo especialmente construído para auxiliar na compreensão de um modelo consensual).

Portanto, no tocante aos modelos pedagógicos, Gilbert e Boulter (1998) indicam que o seu uso visa à promoção de meios específicos de compreensão dos modelos consensuais pelos estudantes, de tal modo que "o modelo pedagógico se torna a fonte a partir da qual se desenvolve um modelo mental aceitável do modelo consensual".

A proposição de metodologias e/ou métodos que possibilitem uma aprendizagem mais eficiente e significativa tem sido um dos maiores motivos de preocupação entre os docentes e pesquisadores, assim, vários autores têm publicado trabalhos apresentando estratégias e recursos 
didáticos diferenciados que visem facilitar e aprimorar o processo de ensino e aprendizagem. No que se refere a esse respeito, eles propõem o uso de modelos didáticos como interessante recurso pedagógico. De acordo com Della Justina et al. (2003), um modelo didático corresponde a um sistema figurativo que reproduz a realidade de forma esquematizada e concreta, tornando-a mais compreensível ao estudante.

Para Cavalcante e Silva (2008), os trabalhos com modelagem didática permitem estratégias de experimentação, oportunizando que os estudantes possam aliar teoria e prática, propiciando condições para que os conceitos abordados em certo conteúdo sejam compreendidos, além de atuar no desenvolvimento de competências e habilidades.

Na visão de Krasilchik (2004), os avanços científicos no campo da biologia têm conduzido à necessidade de uma didatização dos conhecimentos nas salas de aula de ciências, isto é, à facilitação dos conhecimentos científicos biológicos em objetos de ensino.

Diante dos expostos acima, pode-se complementar que o trabalho de modelagem didática como recurso auxiliar em determinada prática pedagógica pode ser amplamente eficaz no ensino e aprendizagem de conteúdos (especialmente aqueles que são complexos, rebuscados e de difícil compreensão). No entanto, é de fundamental importância que o professor tenha uma formação adequada para o trabalho com modelos didáticos que favoreça uma satisfatória abordagem e construção de conceitos.

A utilização de modelos didáticos para o ensino de conceitos de biologia celular, tendo como base a Teoria de David Ausubel pode potencializar a aprendizagem. Particularmente para o assunto citoplasma celular, onde diversos mecanismos metabólicos indispensáveis à sobrevivência e manutenção da célula ocorrem, que exige do estudante características como abstração, imaginação e paciência, a elaboração de diversos modelos didáticos tridimensionais nestas condições de estudo pode facilitar a assimilação dos conceitos e, principalmente, tornar as aulas mais interessantes, motivadoras, produtivas e que proporcionem ao estudante maior capacidade de relacionar o conteúdo com o seu dia a dia.

Tendo Mapas Conceituais como parâmetro de análise, a pesquisa buscou verificar se o uso de modelos didáticos pode ser utilizado como meio potencialmente significativo para a construção de um modelo consensual e para efetivar a Aprendizagem Significativa de conceitos de biologia celular. Assim, objetivou-se neste trabalho investigar as possíveis aproximações da aplicação da atividade de modelagem didática na perspectiva Ausubeliana e os princípios facilitadores da Aprendizagem Significativa.

\section{A TEORIA DE AUSUBEL E OS MAPAS CONCEITUAIS}

Segundo Teoria de Ausubel, a aprendizagem é dita significativa "quando uma nova informação (conceito, idéia, proposição) adquire significados para o aprendiz através de uma espécie de ancoragem em aspectos relevantes da estrutura cognitiva preexistente do indivíduo, em conceitos, idéias, proposições já existentes em sua estrutura de conhecimentos (ou de significados) com determinado grau de clareza, estabilidade e diferenciação" (MOREIRA, 1988, p.5).

Nesta abordagem há uma interação "entre o novo conhecimento e o já existente, na qual ambos se modificam. À medida que o conhecimento prévio serve de base para a atribuição de 
significados à nova informação, ele também se modifica, adquirindo novos significados, se tornando mais diferenciados, mais estáveis" (MOREIRA, 1988, p.5). A estrutura cognitiva está constantemente se reestruturando durante a Aprendizagem Significativa.

Outro fator de extrema relevância para efetivar uma Aprendizagem Significativa é o envolvimento do aluno com o tema a ser estudado, ou seja, a sua predisposição para aprender. É preciso resgatar o interesse dos alunos, o professor tem que estar disposto a inovar os recursos pedagógicos para tornar as aulas mais agradáveis. Caso contrário, se "o indivíduo quiser memorizar o conteúdo arbitrária e literalmente, então a aprendizagem será mecânica" (PELIZZARI et al, 2002, p.38).

A Aprendizagem Significativa subordina-se, especialmente, a dois princípios: diferenciação progressiva, reconciliação integrativa, organização sequencial e consolidação. O primeiro princípio, diferenciação progressiva, implica a hierarquização dos conceitos por sua disposição dos mais abrangentes até os mais específicos, objetivando respeitar duas hipóteses: uma, de que é mais fácil apreender e discriminar um conjunto de características de um corpo de conhecimento quando se tem por ponto de partida os conceitos mais abrangentes, generalizáveis e inclusivos e, por ponto de chegada, aqueles menos abrangentes, generalizáveis e inclusivos; a outra hipótese de que aprender implica a organização hierárquica do conteúdo na estrutura cognitiva (AUSUBEL et al 1980; MOREIRA, 2006). Enquanto implicação para a consecução do ensino decorre a proposição dos conceitos gerais e menos diferenciados de uma disciplina ou unidade informacional, para os específicos e particulares, de tal modo que

[...] um tópico servirá de idéia ou idéias de esteio para os subtópicos em que se subdivide; ou ainda, na sequência dos tópicos, se ordenados com o princípio da diferenciação progressiva, aqueles que vierem antes fornecerão base de assimilação ou esteio para os que vierem depois (FARIA, 1989, p. 29).

O segundo princípio, reconciliação integrativa, envolve o estabelecimento de relações e correlações entre os conceitos a integrarem a hierarquia,pela ampliação no delineamento das distinções e similitudes que os particularizam (AUSUBEL et al 1980; FARIA, 1989; MOREIRA, 2006). Atender esse princípio no contexto educativo pressupõe cuidado na programação do material instrucional a ser utilizado, pois ele deve ser concebido e organizado de maneira a favorecer a exploração de relações entre ideias, a indicação de semelhanças e de diferenças entre elas, bem como harmonizar inconsistências, quer sejam elas reais ou aparentes.

A abordagem dos Mapas Conceituais está fundamentada na Teoria de Ausubel, entendendo que o indivíduo constrói seu conhecimento e seus significados a partir da sua predisposição para realizar essa construção, que serve como instrumento para facilitar o aprendizado do conteúdo sistematizado em conteúdo significativo para o aprendiz.

Mapeamento Conceitual é uma técnica de análise que pode ser usada para ilustrar a estrutura conceitual de uma fonte de conhecimentos. Essa ilustração é chamada de Mapa Conceitual. Desenvolvidos por Joseph D. Novak, na Universidade de Cornell em 1960, são ferramentas que servem para organizar e representar conhecimentos (NOVAK, 1977).

Os Mapas Conceituais, conforme Moreira (1987) podem ser usados para mostrar relações significativas entre conceitos ensinados em uma única aula, em uma unidade de estudo ou em um 
curso inteiro. São representações concisas das estruturas conceituais que estão sendo ensinadas e, como tais, provavelmente facilitam a aprendizagem dessas estruturas.

De acordo com Cardozo (2005), os Mapas funcionam como uma ponte entre o que o aluno já sabe e a aprendizagem que está a realizar. Podem ser ampliados, o que não dificulta a leitura, quando são feitos de modos apropriados. Com o aspecto de um diagrama esquemático, representam o modo como o aluno trabalha e incorpora no seu esquema mental os novos conceitos que aparecem destacados, bem como as relações significativas entre eles. Sendo assim, os recursos esquemáticos dos Mapas Conceituais servem para tornar claro aos professores e alunos as relações entre conceitos de um conteúdo aos quais deve ser dada maior ênfase (NOVAK, 2000).

A produção de Mapas Conceituais pode promover o desenvolvimento da criatividade e do pensamento reflexivo tão importante no Ensino de Ciências. O que representa a valorização da construção e reconstrução do conhecimento, visto que, por meio dele o aluno tem a possibilidade de compartilhar significados, discutir, negociar e evoluir em sua aprendizagem.

\section{METODOLOGIA}

O trabalho foi desenvolvido com estudantes dos cursos técnicos integrados em Informática e Agricultura do Instituto Federal de Mato Grosso do Sul, câmpus Ponta Porã. As estratégias metodológicas utilizadas para a pesquisa envolveram as seguintes fases, consecutivas e interdependentes:

- Levantamento Bibliográfico: foi realizada uma revisão bibliográfica para levantamento da quantidade e qualidade dos materiais da área disponíveis, bem como uma elaboração mais específica do quadro teórico do trabalho de acordo com as teorias acima citadas;

- Identificação dos Conhecimentos Prévios: esta fase foi destinada à realização da identificação dos conhecimentos preexistentes e dos subsunçores dos estudantes. Na tentativa de alcançar tal objetivo, foi aplicado um questionário prévio com questões cuidadosamente selecionadas que pudessem abranger o maior número de situações variadas onde conceitos de biologia celular estejam envolvidos;

- Trabalho com os Mapas Conceituais: O passo seguinte foi a apresentação de esclarecimentos quanto às formas e possibilidades de construção de um mapa conceitual: importância de selecionar conceitos significativos em um campo informacional, relevância de classificar e seriar os conceitos hierarquicamente e, ainda, conveniência de dispor de boas "palavras de ligação" para esclarecer o sentido das conexões estabelecidas. Após isso, foi o conteúdo de biologia celular foi discutido por meio de um Mapa Conceitual de referência (Imagem 1). Foi proposto aos alunos a confecção de Mapas Conceituais relacionados aos conteúdos de biologia celular, um antes e um depois das intervenções em sala de aula com os modelos didáticos; 


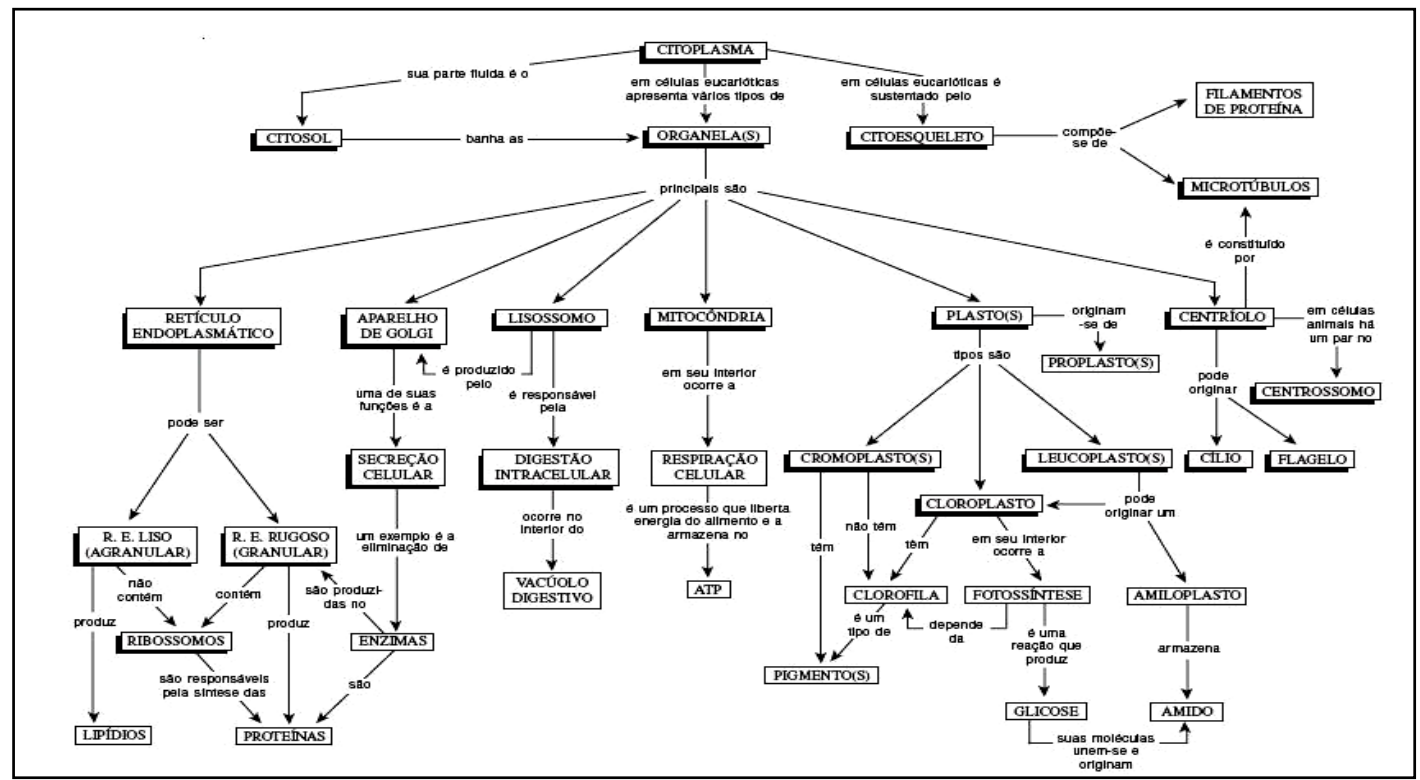

Figura 1:Mapa conceitual sobre organelas citoplasmáticas. Fonte: Amabis\&Martho, 2001.

- Confecção dos modelos didáticos: Os estudantes foram divididos em grupos, onde cada grupo desenvolveu um modelo didático diferente com tipos celulares/virais e representações de seres vivos estipulados pelo docente. Os estudantes tiveram total liberdade de escolha dos materiais que iriam utilizar. Soluções criativas, não convencionais e especialmente aquelas que exigem menos recursos e materiais de baixo custo foram estimuladas. Em data estipulada pelo docente, os grupos apresentaram seus modelos desenvolvidos (em forma de seminário) e ocorreu discussão geral dos mesmos, onde foi registrada e analisada as interações com seus pares e com o professor.

- Como mais um instrumento de pesquisa, utilizado para verificar evolução ou desenvolvimento conceitual, foi aplicado um questionário (pré-teste) para que pudesse ser verificado a compreensão dos conceitos e assuntos bastante básicos apresentados inicialmente sobre o conteúdo de citologia. Após as intervenções (com as atividades em sala de aula e com os modelos didáticos) um outro questionário (pós-teste) com questões similares foi novamente aplicado objetivando uma análise comparativa sobre o desempenho da aprendizagem dos alunos.

\section{RESULTADOS E DISCUSSÃO}

A proposta de produção de materiais pedagógicos e lúdicos com reutilizáveis vai ao encontro da tendência atual que se instaura no Ensino de Ciências e Biologia, uma vez que contempla o uso de uma metodologia diferenciada e que valoriza a participação ativa dos estudantes, distanciando-se assim das aulas "tradicionais" vinculadas a metodologias passivas, com o uso exclusivo do livro didático.

Ao propor tal estratégia objetivava-se a revisão dos conceitos por parte dos discentes (visto que já tiveram tais conteúdos nos anos anteriores), assim como propiciar momentos para o desenvolvimento de um modo de ensinar, colocando-o em uma situação prática e coletiva de planejamento didático-pedagógico.

A estratégia da produção e apresentação de modelos didáticos possibilitou dinamizar as aulas que, de forma geral, apresentam um corpo teórico muito rebuscado, uma vez que a partir da 
análise e observação dos trabalhos construídos foi possível perceber a argumentação em torno dos eixos propostos para o desenvolvimento dos materiais, o de divulgação científica e o de ensino. Além disso, foram proporcionados momentos de fundamentação teórica para a prática do ensino de citologia, uma vez que os estudantes procuraram embasar seus argumentos com a literatura científica dos livros didáticos, internet e revistas/artigos científicos na área da Biologia, expressando a busca pela relação entre a teoria e prática.

Ficou expresso na produção que os resultados da atividade constituíram-se em modelos das estruturas biológicas e que partem do princípio da necessária interação entre o sujeito aprendente e o objeto a ser apreendido para ocorrer a construção do conhecimento. Assim, uma vez que o estudo da biologia celular pauta-se sobre estruturas que muitas vezes não podem ser vistas a olho nu, os recursos bidimensionais e tridimensionais puderam atuar como o objeto nesta interação.

Segundo Orlando et al (2009), o ensino de tópicos de Biologia celular constitui um dos conteúdos do Ensino Médio de Biologia que mais requer a elaboração de material didático de apoio ao conteúdo presente nos livros texto, já que emprega conceitos bastante abstratos e trabalha com aspectos microscópicos. Dessa forma, os autores preconizam que modelos biológicos como estruturas tridimensionais ou semi-planas (alto relevo) e coloridas são utilizadas como facilitadoras do aprendizado, complementando o conteúdo escrito e as figuras planas e, muitas vezes, descoloridas dos livros-texto. Além do lado visual, esses modelos permitem que o estudante manipule o material, visualizando-o de vários ângulos, melhorando, assim, sua compreensão sobre o conteúdo abordado. Para os deficientes visuais, é uma ferramenta bastante eficaz, uma vez que a diferença de textura e tamanho dos materiais utilizados na construção do modelo é um quesito primordial auxiliar no sentido do tato, bastante explorado por esses alunos.

Quanto ao comparativo dos testes (pré e pós), foi organizado um conjunto de informações com algumas categorias, onde o docente conseguiu verificar, para alguns conteúdos, alguns pontos importantes de avanços na aprendizagem dos estudantes. Juntamente ao item referente ao conteúdo, foram inseridos nesse trabalho algumas imagens de modelos didáticos utilizados, representando o esquema prático após a apresentação dos grupos (Figuras 2 a 5).

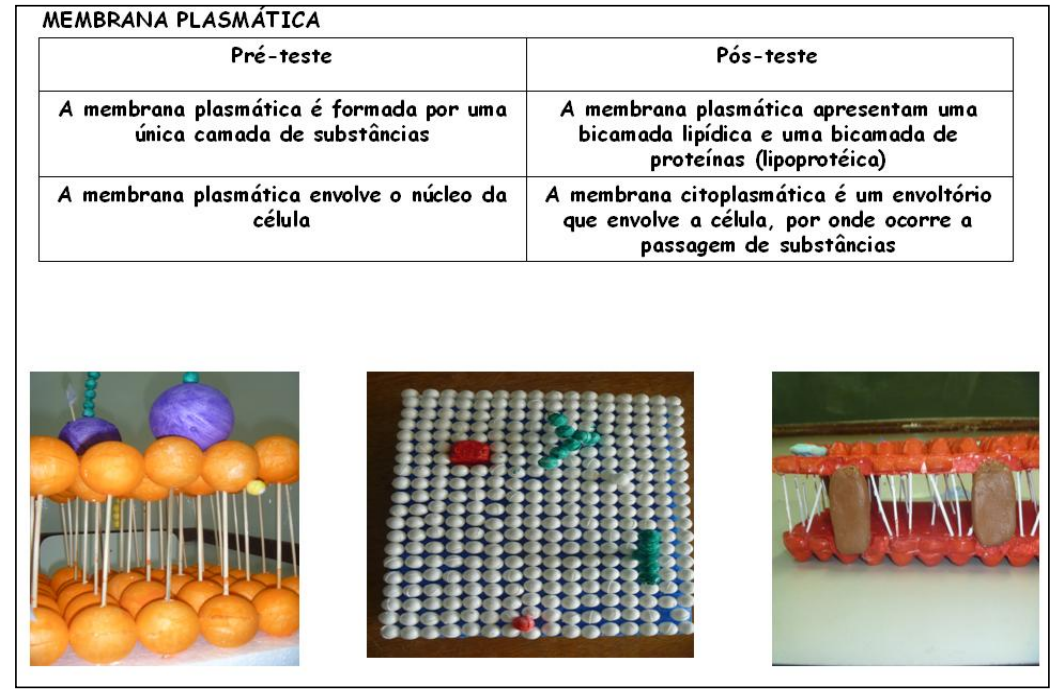

Figura 2: Figura com algumas considerações, por categorias de análise, de respostas de estudantes no pré-teste e no pós-teste. Alguns modelos didáticos sobre o conteúdo de membrana plasmática. 


\begin{tabular}{|c|c|}
\hline VÍRUS Pré-teste & Pós-teste \\
\hline $\begin{array}{c}\text { Vírus são não são seres vivos e são } \\
\text { unicelulares }\end{array}$ & $\begin{array}{c}\text { Vírus são seres vivos mas não possuem } \\
\text { estrutura celular }\end{array}$ \\
\hline Vírus apresentam DNA e RNA & $\begin{array}{c}\text { Os vírus apresentam somente um material } \\
\text { genético, com exceção do citomegalovírus }\end{array}$ \\
\hline Vírus são bactérias & $\begin{array}{c}\text { Vírus não pertencem a nenhum dos cinco } \\
\text { reinos da natureza }\end{array}$ \\
\hline
\end{tabular}

Figura 3: Figura com algumas considerações, por categorias de análise, de respostas de estudantes no pré-teste e no pós-teste. Alguns modelos didáticos sobre o conteúdo de vírus.

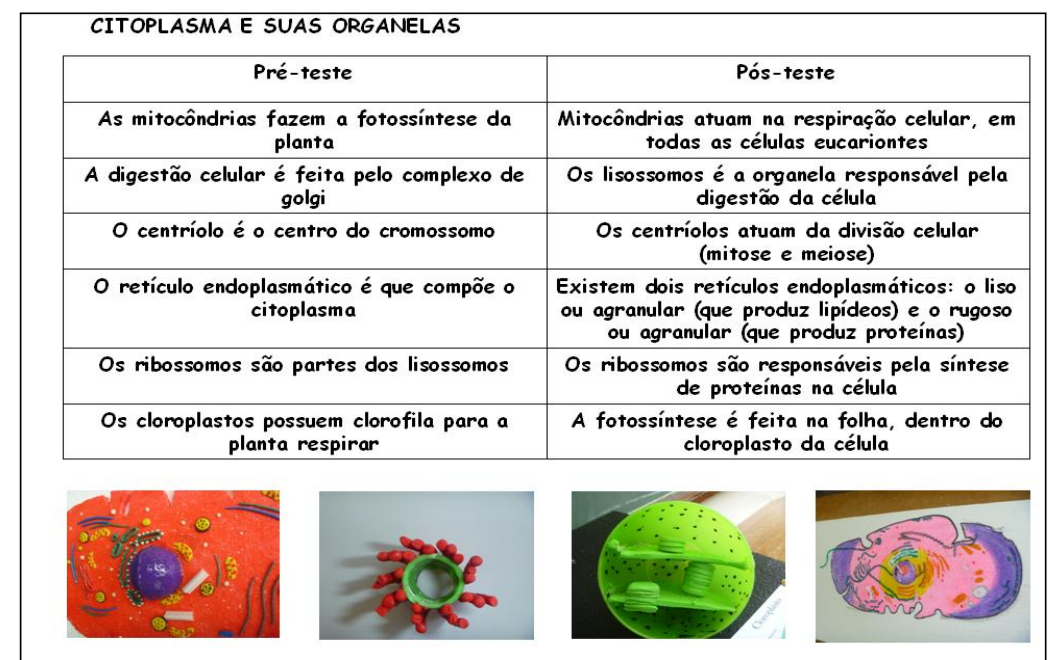

Figura 4: Figura com algumas considerações, por categorias de análise, de respostas de estudantes no pré-teste e no pós-teste. Alguns modelos didáticos sobre o conteúdo de citoplasma e suas organelas.

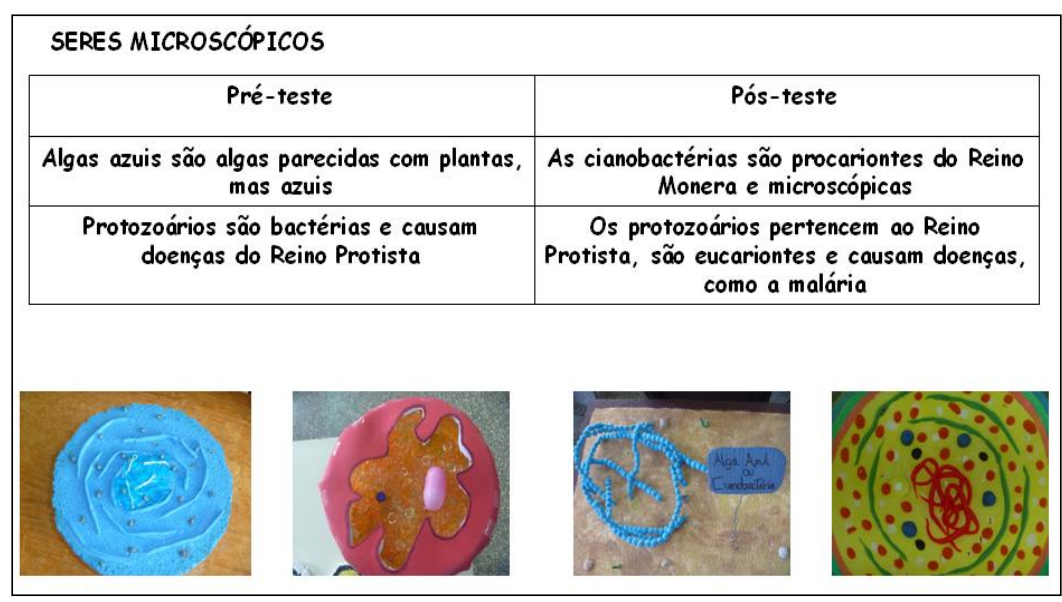

Figura 5: Figura com algumas considerações, por categorias de análise, de respostas de estudantes no pré-teste e no pós-teste. Alguns modelos didáticos sobre o conteúdo de seres microscópicos. 
Os Mapas Conceituais construídos pelos alunos foram analisados quali-quantitativamente e, como finalidade adicional, buscou-se avaliar a opinião dos alunos acerca das potencialidades deste instrumento para facilitar a aprendizagem e, em particular, a sua contribuição para a expressão escrita, as dificuldades percebidas na construção de seus diagramas, as vantagens e desvantagens de seu uso.

Um Mapa Conceitual pode ser traçado manualmente, com o uso de softwares apropriados ou adaptados, ou seja, qualquer software que tenha suporte para textos e figuras. Como exemplo de softwares próprios para a construção de Mapas Conceituais, pode ser citado o Cmap Tools, desenvolvido pelo Institute for Humanand Machine Cognition (IHMC), uma unidade de pesquisada Universityof West Florida, estabelecida em 1990, disponível na página da internet: http://www.cmap.ihmc.us/.

Assim, os Mapas Conceituais construídos pelos alunos foram reproduzidos em scanner e posteriormente passados para o programa Cmap Tools, que é um dos mais populares programas para construção e compartilhamento de Mapas Conceituais. A opção por também apresentar os mapas na versão desse software foi no sentido de otimizar a visualização dos mesmos, uma vez que muitos mapas em versão original foram feitos a lápis, o que possivelmente dificultaria sua observação e visualização.

Alguns exemplos de Mapas Conceituais estarão apresentados a seguir, como forma de se visualizar as diferentes possibilidades e estratégias de criação dos Mapas confeccionados pelos alunos (Figuras 6 a 10).

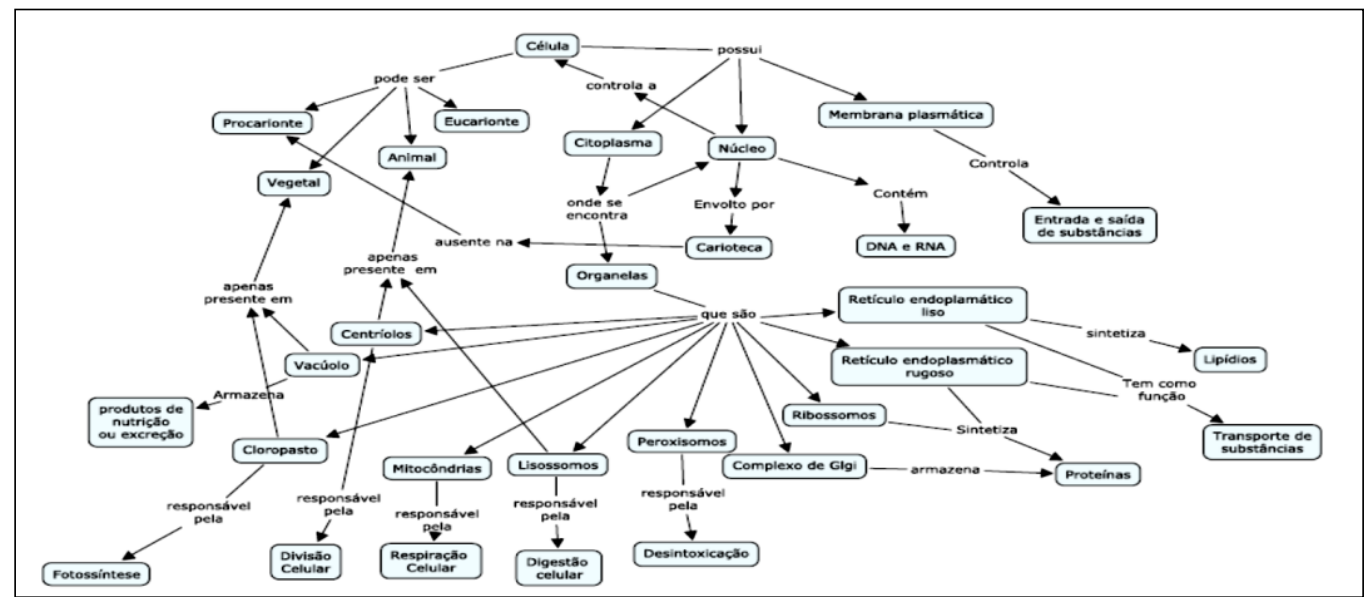

Figura 6: Mapa Conceitual construído por estudante do 10 semestre do curso de Informática - IFMS 


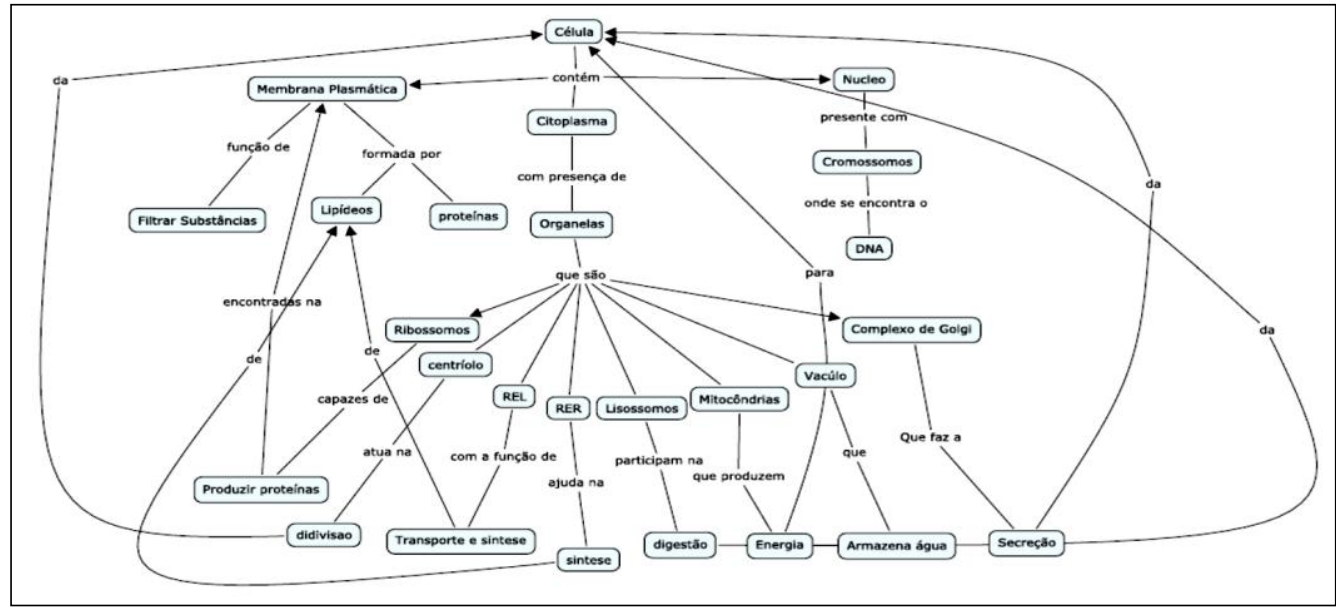

Figura 7: Mapa Conceitual construído por estudante do 1 semestre do curso de Informática - IFMS

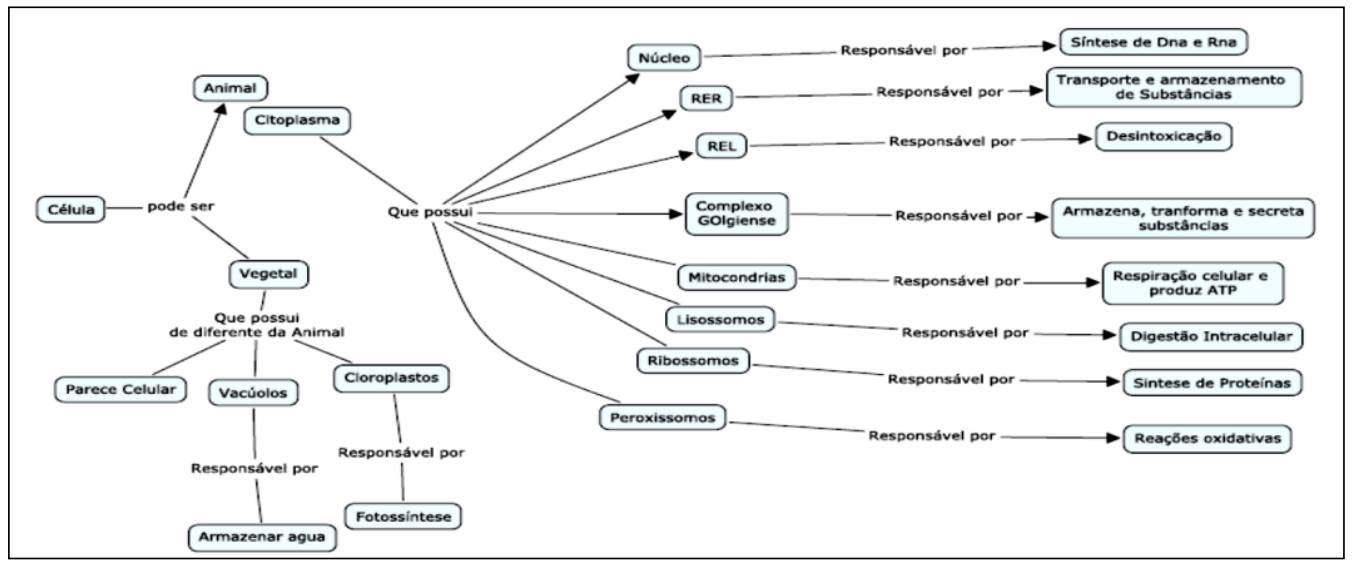

Figura 8: Mapa Conceitual construído por estudante do 10 semestre do curso de Agricultura - IFMS

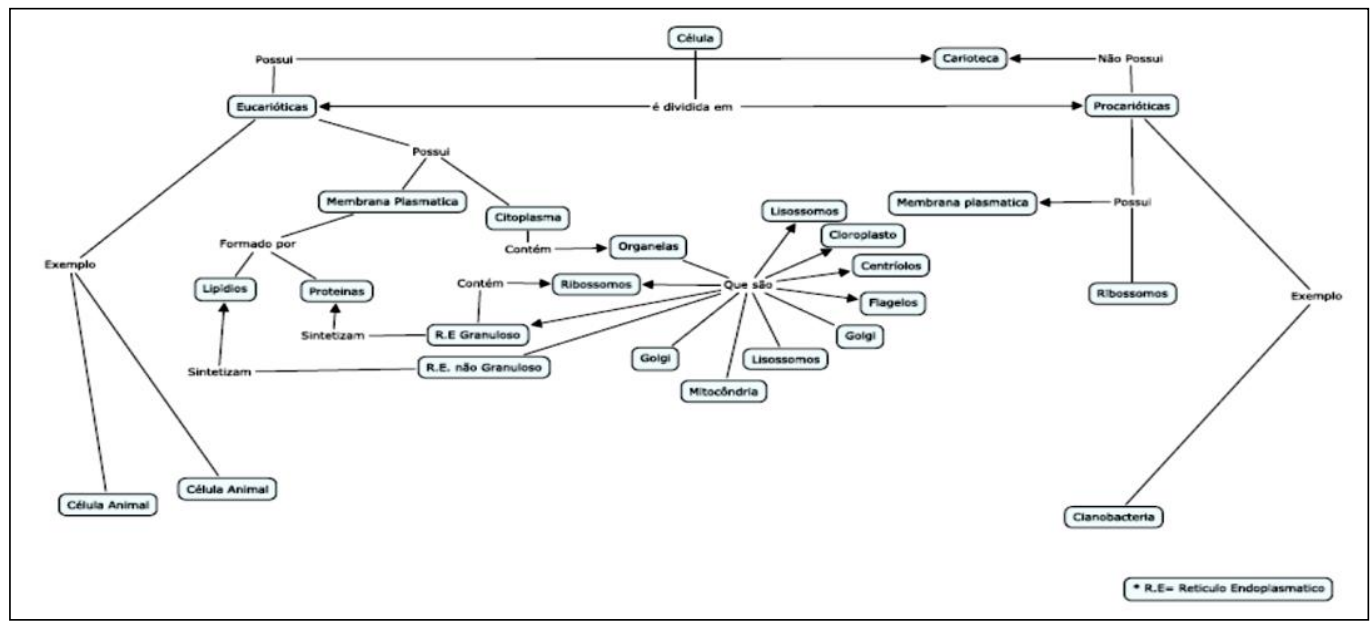

Figura 9: Mapa Conceitual construído por estudante do 10 semestre do curso de Agricultura - IFMS 


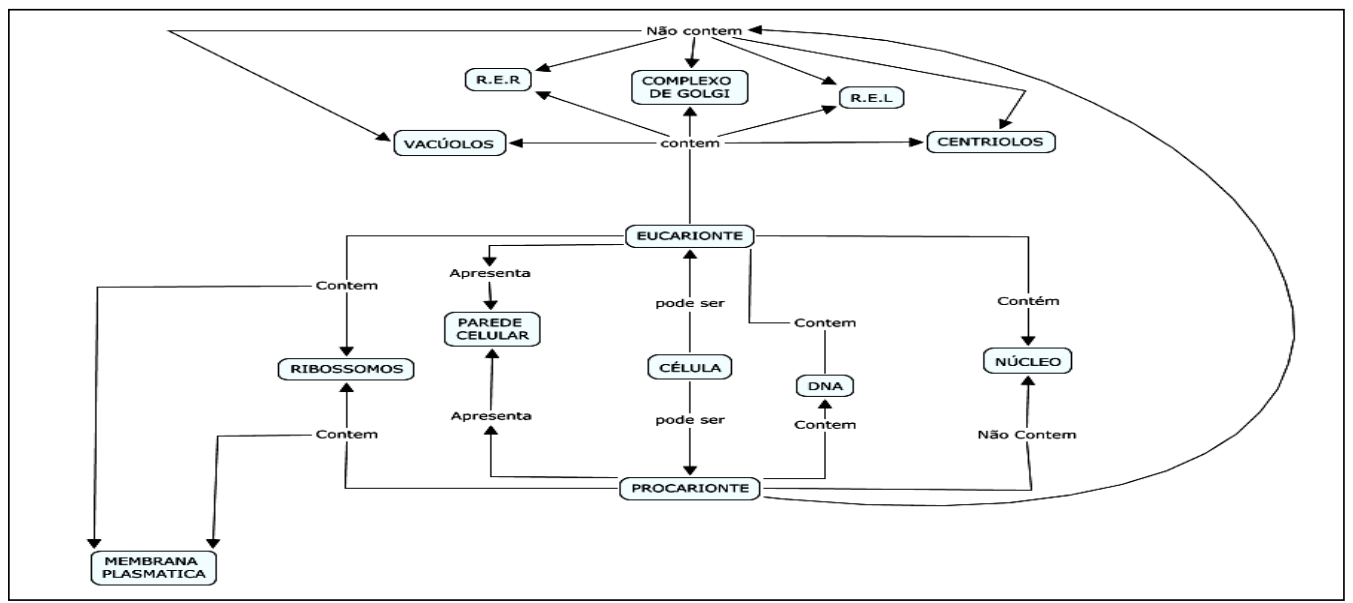

Figura 10: Mapa Conceitual construído por estudante do 10 semestre do curso de Informática - IFMS

Os estudantes apresentaram Mapas Conceituais com várias relações de significados e palavras de ligação identificadas, mapas com várias relações de significados sem palavras de ligação identificadas e Mapas Conceituais superficiais.

Os estudantes enfrentaram certa dificuldade na confecção dos Mapas Conceituais, observando-se um desenvolvimento "mediano", contudo, vários estudantes que se demonstravam desinteressados e apáticos com a nova prática adotada, ao final do processo, se mostraram motivados e buscando participar de forma ativa com as atividades propostas.

Em diversos Mapas Conceituais construídos, os conceitos-chave foram ligados por mais de uma palavra de ligação com outros conceitos, fato que não gerou comprometimento a "visualização" do raciocínio e a clareza dos dados. Alguns conectores se apresentaram um pouco extensos, em alguns casos, formando frases, talvez, visando criar um mapa mais fidedigno possível.

A falta de conhecimento e experiência para construção de Mapas Conceituais pode ter sido fator de dificuldades de exposição das ideias sobre o conteúdo trabalhado. No entanto, a utilização e confecção de mapas pelos estudantes podem ser ricos instrumentos utilizados para verificação de evolução conceituas e ocorrência de Aprendizagem Significativa.

Essa estratégia contribuiu não somente para a Aprendizagem Significativa, mas também para o desenvolvimento de competências e habilidades dos alunos.

\section{CONSIDERAÇÕES FINAIS}

Encontrar alternativas para tornar as aulas de Biologia Celular motivadoras e proporcionar aos estudantes a Aprendizagem Significativa é um desafio constante para grande parte dos docentes desta disciplina.

As atividades que exploram modelagem didática como recurso alternativo ao aprendizado, nesta pesquisa, estimularam o envolvimento dos estudantes com o conteúdo e provocaram situações peculiares à ludicidade. A estratégia guiada pelos pressupostos do desenvolvimento cognitivo explorou o lúdico, fator ímpar na observação do exercício dos estudantes em desenvolver habilidades que atuaram na aprendizagem de conteúdos de biologia celular.

Além do ambiente descontraído e substancial, um outro aspecto observado foi a predisposição do aluno para aprender, fator fundamental para que ocorra Aprendizagem 
Significativa nos pressupostos de David Ausubel. Essa característica foi percebida na execução da atividades, na integração estabelecida, do pensamento e da ação, com conseqüente apropriação de termos científicos na escrita, nas apresentações dos modelos e no aprimoramento cognitivo com aplicação viável para situações-problemas do cotidiano e na construção de significados para o aprendiz.

Apesar das dificuldades na estruturação dos Mapas Conceituais, assim como, na colocação de proposições para formação lógica do raciocínio, a maioria dos estudantes se identificou com este recurso didático. Percebeu-se, também, maior eficácia na capacidade de diálogo entre os grupos, bem como de trabalhar coletivamente, porém, com certa dificuldade para definir, relacionar conceitos e organiza-los de forma hierárquica.

A viabilidade do uso de Mapas Conceituais em um tipo de atividade que envolve novidades e descobertas, depende da forma como a prática foi adotada e utilizada pelo docente. $\mathrm{O}$ uso assíduo de mapeamento conceitual como estratégia didática exercita o estudante a sistematizar seus conhecimentos iniciais, ancorando-os ao novo conhecimento, bem como, compartilhar seus significados entre os colegas e o professor.

Espera-se que por meio dos dados obtidos nesta pesquisa, fiquem explícitas as contribuições que os modelos didáticos aliados ao mapeamento conceitual fundamentado na Teoria de Ausubel, como mediadores dos conhecimentos em biologia celular, proporcionam ao ensino e aprendizagem destes conteúdos. Buscou-se estimular o prazer pela compreensão de temáticas rebuscadas e difíceis do conteúdo biológico, inserindo metodologias em que o conhecimento esteja ligado ao lúdico.

\section{REFERÊNCIAS}

1. AUSUBEL, D.P., NOVAK, J.D., HANESIAN, H. Psicologia Educacional (2a ed., E. Nick; H. B. C. Rodrigues; L. Peotta; M. A. Fontes; M. G. R. Maron, Trad.) Rio de Janeiro: Interamericana. 1980.

2. CARDOZO, S.M.S. Análise crítica do Ensino de Ciências nas séries iniciais do ensino fundamental em Boa Vista-RR: construindo diagnóstico e propondo alternativas metodológicas e de conteúdos. Dissertação de Mestrado. Universidade Luterana do Brasil. Canoas, 2005. 219p.

3. CARVALHO, A.M.P. de. A pesquisa no ensino, sobre o ensino e sobre a reflexão dos professores sobre seus ensinos. In: Educação e Pesquisa, São Paulo, vol.28, p.57- 67, 2002.

4. CAVALCANTE, D.D., SILVA, A. de F.A. de. Modelos didáticos e professores: concepções de ensino-aprendizagem e experimentações. In: XIV Encontro Nacional de Ensino de Química, Curitiba, UFPR, Julho de 2008. Disponível em http://www.quimica.ufpr.br/eduquim /eneq2008/resumos/R519-1.pdf. Acessado em 13/12/2013.

5. CLEMENT, J. Model based learning as a key research area for science education. Journal of Science Education, v. 22, p. 1041-1053, 2000.

6. DELLA JUSTINA L.A.; RIPPEL J.L.; BARRADAS C.M.; FERLA M.R. Modelos didáticos no ensino de Genética In: Seminário de extensão da Unioeste, 3., Cascavel. Anais do Seminário de extensão da Unioeste. Cascavel; 2003. p.135-40.

7. FARIA, W. de. Aprendizagem e planejamento de ensino. São Paulo: Ática, 1989. 
8. GILBERT, J.K e BOULTER, C. J. Aprendendo ciências através de modelos e modelagem. In: Modelos e educação em ciências. Colinvaux, D. (org). Rio de Janeiro: Ravil,12- 34,1998.

9. KRASILCHIK, M. Práticas do ensino de biologia. São Paulo: EDUSP, 2004.

10. MOREIRA, M.A. A Teoria da Aprendizagem Significativa e sua implementação em sala de aula. Brasília: Universidade de Brasília, 2006.

11. MOREIRA, M. A. Mapas Conceituais - Instrumentos didáticos, de avaliação e de análise de currículo. São Paulo: Moraes, 1987.

12. MOREIRA, M.A. Mapas Conceituais e Aprendizagem Significativa. Revista Galáico Portuguesa de Sócio-Pedagogia e Sócio-Linguística, Pontevedra/Galícia/Espanha e Braga/Portugal, n. 23 a 28, 87-95, 1988. Disponívelem: http://www.if.ufrgs.br/ moreira/mapasport.pdf

13. NOVAK, J.D. A Theory of education.Nova York: Cornell, University Press, 1977.

14. NOVAK, J.D. Apreender Criar e Utilizar o Conhecimento: Mapas Conceituais como Ferramentas de Facilitação nas Escolas e Empresas. Lisboa: Plátano, 2000.

15. ORLANDO, T.C.; LIMA, A.R.; SILVA, A.M.; FUSISAKI,C.; RAMOS, C.L.; MACHADO, D.; FERNANDES, F.F.; LORENZI, J.C.C.; LIMA, M.A.; GARDIM,S.; BARBOSA, V.C.; TREZ, T.A. Planejamento, montagem e aplicação de modelos didáticos para abordagem de Biologia Celular e Molecular no Ensino Médio por graduandos de Ciências Biológicas. Revista Brasileira de Ensino de Bioquímica e Biologia Molecular, v. 10, p. p.1-17, 2009.

16. PElIZZARI, A., KRIEGL, M.L., BARON, M.P., FINCK, N.T.L., DOROCINSKI, S.I. Teoria da Aprendizagem Significativa Segundo Ausubel. Revista PEC. Curitiba, v.2, 37-42, 2002.

17. SETÚVAL, F.A.R., BEJERANO, N.R.R. Os modelos didáticos com conteúdos de Genética e a sua importância na formação inicial de professores para o ensino de ciências e biologia. In: VII Encontro Nacional de Pesquisa em Educação em Ciências. Florianópolis, 2009. 